\title{
Exploring the Association Between Anxiety and Conduct Problems in a Large Sample of Twins Aged 2-4
}

\author{
Alice M. Gregory, ${ }^{1 ; 2}$ Thalia C. Eley, ${ }^{1}$ and Robert Plomin ${ }^{1}$ \\ 1Social, Genetic, \& Developmental Psychiatry Centre, Institute of \\ Psychiatry, King's College, London, United Kingdom. \\ 2Address all correspondence to Alice M. Gregory, Box PO80, Social, \\ Genetic, \& Developmental Psychiatry Centre, Institute of \\ Psychiatry, De Crespigny Park, London, SE5 8AF, United Kingdom; \\ e-mail: a.gregory@iop.kcl.ac.uk.
}

\begin{abstract}
Anxiety and conduct problems covary, yet studies have not explored the genetic and environmental origins of this association.We analyzed parent-reported anxiety and conduct problems in 6,783 pairs of twins at 2-, 3-, and 4-years of age. As anxiety and conduct problems were fairly stable across the three ages (average 1-year correlation was .53), ratings from all three were combined. The aggregate anxiety and conduct ratings correlated .33 for boys and .30 for girls. Bivariate genetic analyses indicated fairly low genetic correlations ( .31 for boys, .16 for girls), and high shared environmental correlations (1.0 for boys and 0.99 for girls) between anxiety and conduct problems. Most of the phenotypic correlation was accounted for by shared environmental mediation (65\% for boys and 94\% for girls), indicating that many of the same family environmental factors are responsible for the development of both anxiety and conduct problems.
\end{abstract}

Keywords: anxiety; conduct; twins; genes; environment. 
Anxiety and conduct problems are common areas of difficulty in child psychopathology (Anderson, Williams, McGee, \& Silva, 1987). Although each may appear alone these problems also co-occur in both epidemiological and clinic-referred samples (Fergusson \& Horwood, 1993; Russo \& Beidel, 1994). This is interesting because at first glance the symptoms of anxiety appear to be counter indicative of conduct problems, and the presumed causes of anxiety and conduct problems would seem to imply a negative association. Although estimates as to the degree of overlap between anxiety and externalizing problems vary between studies, a reviewof the literature has reported that between 2 and $21 \%$ of children referred for anxiety had externalizing problems (Russo \& Beidel, 1994). Some of the studies leading to these estimates combine child and adolescent data, and co-occurrence between anxiety and externalizing problems may be greater in preadolescent as compared to adolescent samples. For example, in a study of children diagnosed with overanxious disorder, $61 \%$ of those aged $5^{-11}$ were also diagnosed with an externalizing disorder, but only $15 \%$ of those aged $12-19$ received such a diagnosis (Strauss, Lease, Last, \& Francis, 1988).

Over the past decade there has been interest in using genetic data to examine the origins of associations between traits (for a textbook on behavioral genetics see Plomin, DeFries, McClearn, $\&$ McGuffin, 2001). Such data can be used to estimate the extent to which associations are mediated by genes, shared environment (any environmental influence contributing to the resemblance of family members) and nonshared environment (environmental factors not contributing to the resemblance of family members). An example of genetic mediation of the association between anxiety and conduct could be via the serotonin system-which has been associated with both anxiety and conduct problems (Eley, Collier,\&McGuffin, 2002; Unis et al., 1997), although as discussed later most genetic research suggests that genetic factors operate differently for anxiety and conduct. Shared environmental factors, such as parenting style could also influence both anxiety and conduct (Barrett, Rapee, Dadds, \& Ryan, 1996). Finally, nonshared environmental factors, such as peer relationships, could influence both anxiety and conduct. For example, associating with a poorly behaved peer group may result in higher levels of conduct problems (see Windle \& Windle, 1996), and higher levels of anxiety could result from fear of the consequences of such behavior. Understanding the origins of associations between traits is important as it can help direct future research. For example, if behavioral genetic studies show the association between two traits to be entirely mediated by genetic factors, searching for shared environmental influences on this association is not warranted.

Genetic research examining the association between emotional and behavioral problems has tended to focus on problems either within internalizing arenas (e.g., anxiety and depression: Eley \& Stevenson, 1999; Silberg, Rutter, Neale, \& Eaves, 2001; Thapar \& McGuffin, 1997) or within externalizing arenas (e.g., conduct and hyperactivity: Silberg et al., 1996; aggressive and nonaggressive antisocial behavior: Eley, Lichtenstein, \& Moffitt, 2003). Such studies have shown that associations within these domains are largely explained by genetic factors. Only a handful of genetic studies have explored associations between internalizing and externalizing problems in childhood and adolescence and these studies have examined a range of phenotypes and age groups and have yielded conflicting results. A common genetic liability was found to be the most significant indicator of the association between depressive symptoms and antisocial behavior in an adolescent sample (O'Connor, McGuire, Reiss, Hetherington, \& Plomin, 1998; O'Connor, Neiderhiser, Reiss, Hetherington, \& Plomin, 1998) and between internalizing and externalizing problems in 4- to 11-year-old twins (Schmitz \& Mrazek, 2001). In contrast, shared environment was most influential in the association between internalizing and externalizing problem composites in a sample of 2- to 3-year-olds (Schmitz, Cherny, Fulker, \& Mrazek, 1994). This was also found to be the case in 5-9 and 12- to 15-year-olds-especially for the younger group (Gjone\&Stevenson, 1997). The mixed results may in part be due to age and measurement differences between the studies (for a discussion of the effects of age and phenotype on genetic estimates on anxiety, see Eley and Gregory, 2003). However, as they stand, these studies suggest the tentative hypothesis that overlap between anxiety and conduct is due early in development to shared environmental influences and, later in development, to genetic influences. 
Other areas of research provide few clues as to whether genetic, shared environmental, or nonshared environmental influences are important in the positive association between anxiety and conduct problems. For example, although genetic influences on the serotonin system may be important in the association between anxiety and conduct problems, much of the previous research emphasises serotonin differences between these two problems. For example, whole blood serotonin (5-HT) correlates positively with conduct symptoms, but negatively with symptoms of anxiety (Pliszka, Rogeness, Renner, Sherman, \& Broussard, 1988). Similarly, there appears to be an assumption in the literature that shared environmental factors that affect anxiety-such as emotional overinvolvement (for a recent reviewof family processes in the development of anxiety see Dadds \& Roth, 2001) - are different from those that affect conduct problems, such as having a delinquent sibling (Farrington, 1995). Although few studies have explored the effects of family life on anxiety and conduct problems, available studies have yielded contrasting results, with some finding evidence for risk factors impacting on both problems (Barrett et al., 1996; Dadds, Barrett, Rapee, \& Ryan, 1996), and others finding evidence of specificity (Rosenstein\&Horowitz, 1996). Finally, a clear picture of the effects of nonshared environmental factors on the association between anxiety and conduct is lacking. For example, although an increase in stressful life events has been associated with an increase in both emotional and behavioral problems (Berden, Aalhaus, \& Verhulst, 1990), other types of life events can increase one type of problem and diminish another. This was found in a study with a large sample of midadolescents that showed an association between positive daily events, including social engagements with friends, and higher levels of delinquent activity (e.g., peer-associated, age-normative deviant behaviors) and lower levels of depressive affect (Windle \& Windle, 1996).

In summary, although there are many genetic and environmental reasons to think that anxiety and conduct problems are different, a modest positive association exists between them. The few genetic studies of this association have provide mixed results, although they suggest the possibility that shared environmental influences are more important in childhood than later in life. This study provides the first behavioral genetic analysis of the association between anxiety and conduct problems in a sample of preschoolers.

\section{Method}

\section{Participants}

Participants in this study were members of the Twins Early Development Study (TEDS), a longitudinal study of development in which parents of all twins born in England andWales during 1994-95 were invited to participate. Assessments were made at 18 months, 2, 3, and 4 years. At the first assessment 10,932 families were sent booklets to complete. A total of 9,442 of these families (86\%) provided data at the first assessment. From this initial sample, twin pairs were excluded if there were extreme pregnancy or perinatal difficulties (e.g., gestation $<32$ weeks: n D 204) or if either of the twins had an extreme medical condition (e.g., chromosomal abnormalities such as Down's Syndrome and Cerebral Palsy: n D 212).

The present sample included families providing data on anxiety and conduct problems at one or more times during the 2, 3, and 4-year-old assessments. This resulted in a final sample of 6,783 twin pairs: 1,071 monozygotic male (MZM); 1,154 dizygotic male (DZM); 1,217 monozygotic female (MZF); 1,115 dizygotic female (DZF); and 2,226 opposite sex (DZO) twin pairs. Attrition analyses reveal a number of differences between families providing data at 18 months and those providing data at 2, 3, and 4, namely: families remaining in the study are slightly more likely to be White; in the top, or second social class and the father employed, than are those with missing data (see Ronald, Eley, \& Plomin, 2003). Despite attrition, analyses show that the TEDS sample continues to be reasonably representative of parents of young children in the U.K. population in terms of parental ethnicity (94\% White), employment status (father employed: 93\%), and education (for further details see Price, Petrill, Dale, \& Plomin, 2003). Measures A parent-rated instrument to assign zygosity was applied at 18 months and again at 3 and at 4 years of age. This resulted in unambiguously identifying 95\% of the twin pairs 
as monozygotic or dizygotic. For the remaining $5 \%$, DNA was collected from cheek swabs, and zygosity was assigned using a multiplex system, which has an accuracy of more than $99 \%$ (Price, Freeman, Craig, Petrill, Ebersole, Plomin, 2000). SupplementaryDNAis currently being obtained for use in molecular genetic studies (DNA: $n>4000$ twin pairs; Trouton, Spinath, \& Plomin, 2002). Analyses utilising participants DNA indicate that the parent-rated instrument has a $97 \%$ accuracy level (Price et al., 2000). Overall, zygosity was estimated for $99.8 \%$ of the sample.

Parents of the twin pairs completed the Revised Rutter Parent Scale for Preschool children (RRPSPC: Hogg, Rutter, \& Richman, 1997). The RRPSPC is based on the Preschool Behavior Questionnaire, which has been demonstrated to have good reliability (Behar \& Stringfield, 1974). The conduct and anxiety scales in the RRPSPC consist of eight and six items respectively (for a full list of the relevant items see Table I). Parents responded to each item on the RRPSPC on a three-point scale ( $\mathrm{o}=$ not true; 1 = sometimes true; 2 = certainly true).

At 4 years, the wording of some of these items were altered so as to be consistent with the Strengths and Difficulties Questionnaire (SDQ: Goodman, 1997), but items from the RRPSPC that did not correspond to items on the SDQ were also retained allowing creation of very similar scales at all three ages. Factor analysis of the RRPSPC has demonstrated the appropriateness of distinguishing subscales within the RRPSPC (three factors, each with eigenvalues greater than 1 were obtained, corresponding to the anxiety, hyperactivity, and conduct scales: see Ronald et al., 2003). The internal consistencies of the anxiety and conduct scales were excellent (anxiety 2-4 years: $a=.76$; conduct $2-4$ years: $a=.82$ ).

\section{Statistical Analyses}

\section{Data Preparation}

Items in each scale were summed and then converted into percentage scores as a proportion of the total possible score for that scale given the number of items completed. In the rare event that fewer than half the items on a scale were completed, the percentage score was given as missing. The mean of each of these scales at ages 2, 3, and 4 was then calculated to increase both sample size and reliability of the scales. Combining across these ages was considered appropriate as preschool aged children are often age-grouped in the developmental literature.

Furthermore, cross-year correlations were relatively stable $(r=.41-.57)$, and preliminary analyses showed that similar model fitting results were obtained at each age range. The skew statistics for these composite scores were then examined to assess whether transformations to the data were necessary before proceeding with the analyses. The skew statistics were all under 1 and were therefore considered acceptable (anxiety: skewness statistic $=.70, \mathrm{SE}=.03$; conduct: skewness statistic $=.80, \mathrm{SE}=.03$ ), and the data were not transformed. Analyses reported in this investigation are based on these composite scores, unless otherwise indicated.

\section{Twin Analyses}

Twin studies are able to disentangle genetic, shared environmental effects (which make family members resemble one another) and nonshared environmental effects (which do not make family members resemble one another). They do so by comparing within-pair similarity for groups of monozygotic (MZ) twins who are genetically identical, to dizygotic (DZ) twins who share half their segregating genes and 25\% of their dominance effects (Plomin et al., 2001). By comparing MZ and DZ twin correlations it is possible to obtain rough estimates of heritability and environmental influence for a single trait. Furthermore, comparison of twin cross-correlations (e.g., twin 1's anxiety problems score correlates with twin 2's conduct problems score) provides estimates of genetic and environmental contributions to the phenotypic correlation between two traits (Plomin et al., 2001). Structural equation modelling tests the fit of an explicit model, compares the fit of alternative models, and provides confidence intervals for parameter estimates. We used the structural equation modelling package $\mathrm{Mx}($ Neale, 1997) to conduct maximum-likelihood model-fitting analyses of the variance-covariance matrices. Three indices of fit are presented: chisquare $\left(\chi^{2}\right)$; Akaike Information Criterion (AIC); and root mean square error of 
approximation (RMSEA). For all three statistics, lower values indicate superior fit. In very large samples, the $\chi^{2}$ tends to be large and significant, as even small differences between the observed and expected covariance matrices are likely to be significant. For this reason the RMSEA statistic, which takes sample size into consideration, is a better indicator of the model's fit. The model of best fit was assessed by change in chi-square as a function of the change in degrees of freedom.

\section{Bivariate Genetic Analyses}

With no preconceptions as to the nature of the relationship between the two phenotypes, three different bivariate genetic models were fitted to the data to decompose the covariance between anxiety and conduct problems. The first model was the common pathways model (Fig. 1), which proposes that genetic, shared and nonshared environmental factors have an indirect effect by influencing an underlying phenotype (p), which we propose could be something such as emotional reactivity. This phenotype then influences both anxiety and conduct problems. In addition to these shared influences, the common pathways model includes additional additive genetic and nonshared environmental factors specific to each of the phenotypes. As bivariate models can only estimate nine paths at one time, specific shared environmental influences were not included in this model.

The second model was the independent pathways model (Fig. 2). This model allows one set of common (genetic, shared environment, and nonshared environment) influences that predict variance on the two measures. For example, aspects of parenting have been associated with both anxiety and aggression (Barrett, Rapee, Dadds, \& Ryan, 1996) and could act as a shared environmental influence common to both anxiety and conduct. In addition to common influences, this model includes measure specific genetic, shared environmental, and nonshared environmental influences. In order that this model contains no more than nine paths, those from the shared factors were set to have equal influence on each for the two measured variables.

The final model tested was the correlated factors model (Fig. 3), which allows genetic, shared, and nonshared environmental influences on one phenotype to correlate with the same factors on the other phenotype. This means that the correlation between anxiety and conduct problems may result from correlations mediated via genetic routes, shared environment, or nonshared environmental routes. An example of the way in which the shared environmental route maywork is as follows: lowsocioeconomic status (SES) is associated with conduct problems (Johnson, Cohen, Dohrenwend, Link, \& Brook, 1999); low SES is associated with maternal authoritarian parenting and emotional distress (Linver, Brooks-Gunn, \& Kohen, 2002). These latter two factors are related to anxiety in children (for further description of models of comorbidity see Neale \& Kendler, 1995).

For each of these three models we ran two versions- one allowing sexes to differ, the other constraining the solutions for males and females to be the same (for further information about sex limitation models, see Neale and Cardon, 1992). The fit indices of the models were compared and further analyses were based on the model of best fit. The correlation between anxiety and conduct was calculated and the percentage of this correlation due to genetic, shared, and nonshared environmental factors was obtained, by multiplying the estimates for the common paths and dividing by the phenotypic correlation.

\section{Results}

\section{Descriptive Statistics}

Table II shows the mean scores for anxiety and conduct problems by twin type and age. A repeated measures analysis of variance (ANOVA) revealed significant differences for the scores at different ages, $\mathrm{F}(1.6813)=6814: 00, \mathrm{p}<.001 ; \mathrm{F}(1 ; 6772)=458: 07, \mathrm{p}<.001$, for anxiety and conduct problems, respectively. The main age change is a decrease in anxiety and conduct problem scores at the age of 4 . This may be partly due to the use of slightly different items to 
assess anxiety and conduct problems at the age 4 assessment (see Method section) if possible. Despite this decrease in scores, the cross-year correlations are significant, ranging from .41 to .50 for anxiety problems and from .43 to .57 for conduct problems. Sex and zygosity differences for anxiety and conduct scores at 2, 3, 4, and mean were examined using analysis of variance (ANOVA). The mean scores differed significantly with sex and zygosity for each of the phenotypes at each age group, with males scoring slightly higher than females on conduct (males: $M=0.28$, $\mathrm{SD}=.15$; females: $\mathrm{M}=0.24, \mathrm{SD}=.14$ ) and anxiety (males: $\mathrm{M}=0.267, \mathrm{SD}=.15$; females: $\mathrm{M}=$ $0.266, \mathrm{SD}=.15)$. Similarly, DZ twins scored slightly higher than MZ twins on both anxiety (MZ: $\mathrm{M}=0.25, \mathrm{SD}=.14 ; \mathrm{DZ}: \mathrm{M}=0.27, \mathrm{SD}=.15)$ and conduct $(\mathrm{MZ}: \mathrm{M}=0.258, \mathrm{SD}=\mathrm{D} .14 ; \mathrm{DZ}: \mathrm{M}$ $0.260, \mathrm{SD}=.15)$. With this large sample size such small mean differences reach significance. We conducted regression analyses to examine the proportion of variance explained by sex and zygosity on anxiety and conduct. These proportions were small $\left(\beta=-.02, \mathrm{p}<: 05, \mathrm{R}^{2}=.000 ; \beta=\right.$ ${ }^{\circ} .06, \mathrm{p}<: 001, \mathrm{R}^{2}=.004$ for the composite score of anxiety and conduct respectively) and so these mean differences were not considered further.

\section{Twin Correlations}

Table III shows twin correlations for anxiety and conduct problems. This table shows both univariate twin correlations (e.g., the correlation for anxiety problems within MZ male twin pairs is .61) and bivariate correlations (e.g., the correlation between twin 1 for anxiety problems and twin 2 for conduct problems for MZ male twin pairs is .34). As indicated elsewhere (Ronald et al., 2003), the univariate correlations all show MZ similarity to be greater than DZ similarity, especially for anxiety problems, indicating considerable genetic influence. For conduct symptoms the DZ correlations are also high, indicating substantial shared environmental influence. The bivariate cross-twin correlations (anxiety problems in one twin, conduct problems in the other) are lower than the univariate twin correlations because the ceiling for bivariate cross-twin correlations is the phenotypic correlation, which varies from .28-.37 for the five groups. The average bivariate $\mathrm{MZ}$ and same-sex DZ cross-twin correlations between anxiety and conduct problems are .35 and .32 for boys and .33 and .38 for girls. This pattern of bivariate cross-twin correlations suggests strong shared environmental mediation of the association between anxiety and conduct problems, even though the twin correlations of anxiety considered separately shows no evidence for shared environment. The pattern of univariate and bivariate results was similar for same-sex male and female twins, and the results for opposite-sex DZ twins were similar to those for same-sex DZ twins, suggesting no important sex differences in genetic and environmental influences.

\section{Model-Fitting Analyses}

Univariate models of these behavioral problems are reported elsewhere (Ronald et al., 2003). Here, three bivariate models were fitted to the variance-covariance matrices. For each, models were compared in which estimates for the sexes were constrained to be equal, as well as a sex effects version that allowed parameter estimates to differ for boys and girls. Table IV shows that the correlated factors model, with sex differences on the parameter estimates (model 6) provided the best fit to the data. This model had a low $\chi^{2}$ (273.370) and the lowest AIC (209.37), and RMSEA (.06) of all the models, and provided a significantly better fit than the correlated factors model in which the sex differences were constrained to be equal (model 5).

The parameter estimates and 95\% confidence intervals for the best fitting bivariate model are presented in Table $\mathrm{V}$ with separate estimates for boys and girls. For anxiety, additive genetic, shared environment, and nonshared environmental factors all significantly predicted variance in anxiety problems. Although the best fitting bivariate model allowed for sex differences in parameter estimates, the estimates were similar for boys and girls for anxiety. For conduct problems, additive genetic factors, shared, and nonshared environmental factors were also all significant predictors of the variance, but for girls, additive genetic factors showed somewhat less influence and shared environmental factors somewhat more influence than in boys.

The correlations between genetic and environmental influences on anxiety and conduct (e.g., the correlation between genetic influences on anxiety and genetic influences on conduct) illustrate the 
most interesting aspects of these data. For both boys and girls, shared environment influences are almost entirely the same for the two variables $(\mathrm{rC}=1: 00, .99$ for males and females respectively), with a much lower level of overlap between the genetic influences on the two variables $\left(r_{\mathrm{A}}=.31, .16\right.$ for males and females respectively) and even lower for the nonshared environment $\left(r_{\mathrm{E}}={ }^{\circ} .08,{ }^{\circ} .14\right.$ for males and females respectively). The negative $r_{\mathrm{E}}$ reveals a weak tendency for child-specific environmental influences that lead to an increase in one symptom, decreasing the other symptom.

The phenotypic correlations between anxiety and conduct problems were .33 and .30 for boys and girls, respectively. Figure 4 shows the proportion of these phenotypic correlations due to each of the three sources of variance. These proportions were calculated by dividing each bivariate source of covariance by the phenotypic correlation. So, for example, for girls, the proportion of the phenotypic correlation due to genetic factors was calculated by dividing the genetic contribution to the phenotypic correlation $(\sqrt{ } .36 \times .16 \times \sqrt{ } .38 \mathrm{D}) .06$, by the phenotypic correlation-which is .30. Thus, the proportion of covariation between the two variables due to genetic factors is .2 (.06/.30), which means that $20 \%$ of the phenotypic correlation for girls is mediated genetically. For boys, the proportion of covariation between the two variables due to genetic factors is somewhat greater (42\%). As would be expected from the bivariate genetic and environmental correlations, the phenotypic correlation was largely explained by shared environment influences ( $65 \%$ for boys, $94 \%$ for girls). Nonshared environmental influences account for the smallest proportion $\left({ }^{\circ} 8 \%,{ }^{\circ} 15 \%\right.$ for males and female respectively). As mentioned above, a negative nonshared environmental parameter estimate indicates that nonshared environmental influences on the correlation between anxiety and conduct problems operates such that although one influence leads to higher anxiety problems it also leads to lower conduct problems, and vice versa.

\section{Discussion}

In this large study of preschool aged children, the association between parental ratings of young children's anxiety and conduct problems was largely explained by shared-environmental factors influencing both traits. Genetic factors played only a moderate role and nonshared environmental influences contributed little to the associations between these traits. The most interesting finding is that, despite moderate genetic influence and only modest shared environmental influence on parameter estimates of anxiety and conduct problems, shared environmental factors were most important in explaining the phenotypic association between anxiety and conduct problems. The bivariate correlations for shared environment were very high, suggesting that shared environmental factors that account for variance in anxiety problems are similar to those that influence conduct problems.

\section{Shared Environment Effects}

The importance of shared environmental factors for the association between anxiety and conduct problems is particularly interesting given that significant shared environment is relatively rare (Pike \& Plomin, 1996). However, the majority of studies forming this conclusion examine phenotypes separately, and previous research examining associations between behavior problems has also found that shared environmental factors play an important role in covariation between behavioral problems, even though shared environment has only a modest impact on each behavior problem separately (e.g. Gjone \& Stevenson, 1997; Schmitz et al., 1994; Van den Oord, Boomsma, \& Verhulst, 2000). In the present dataset, despite the importance of shared environmental influences on the association between anxiety and conduct problems, shared environment was not important in univariate estimates of anxiety (see Ronald et al., 2003). The finding that there is little shared environment on one of two variables considered separately, but significant shared environment on their association, has been demonstrated previously (e.g., Jaffee, Moffitt, Caspi, Taylor, \& Arseneault, 2002). Although the finding that the covariation between anxiety and conduct is mainly due to shared environmental factors seems at odds with the finding that shared environmental factors do not influence univariate estimates, this is not necessarily the case. This is because model fitting works by 
providing the most parsimonious model of best fit. This means that if shared environmental factors only have a small influence on anxiety they may be dropped from the univariate model. However, if these small influences have an important role in explaining the covariation between traits they will be included in the bivariate model. Furthermore, when looking at cross-twin crosstrait correlations new sources of information are introduced which are used to calculate variable variances as well as covariances. A further possible reason for the importance of shared environmental factors in the this study concerns the use of ratings by one parent only, which could inflate shared environmental estimates. However, other studies of co-occurring problems which have used more than one rater have also shown evidence for shared environment (O'Connor, McGuire et al., 1998; Van den Oord et al., 2000). Conversely, other studies of cooccurring problems in older children have used ratings from single parents and not found evidence for shared environment (e.g. Silberg et al., 1996). Teacher ratings are currently being obtained for the TEDS participants at 7 years to address this issue more closely. Another possible explanation concerns the age of the sample. It is well established that shared environmental influences decrease with age (McCartney, Harris, \& Bernieri, 1990), presumably because people share fewer experiences with their siblings as they grow older. This may help to explain why shared environmental influence on the association between anxiety and conduct is greater here than in previous research using older participants.

Previous research provides relatively few clues as to the type of shared environmental influences increasing risk for both anxiety and conduct problems. Despite the assumption that shared environmental factors that affect anxiety are different from those that affect conduct problems, a handful of studies have highlighted shared environmental factors that may increase both anxiety and conduct problems. The strongest candidate to date is parent-child relationships. For example, parents of children who are either anxious or aggressive tended to agree less with their children and were less likely to point out the positive consequences of situations than were nonclinical control parents (Barrett et al., 1996; Dadds et al., 1996). Furthermore, insecure attachment has been linked to both internalizing and externalizing behavioral problems (van Ijzendoorn \& Bakermans-Kranenburg, 1996; Lewis, Feiring, McGuffog \& Jaskir, 1984), although some research has highlighted specific associations between type of insecure attachment and type of psychopathology. For example, in a study of clinically referred adolescents, children with "dismissing attachment organization" were more likely to have conduct problems, whereas children with "preoccupied attachment organization" were more likely to have anxious traits (Rosenstein\&Horowitz, 1996). Further factors increasing risk for both anxiety and conduct problems include parental psychiatric illness, alcoholism, and discord and divorce (Werry, Reeves, \& Elkind, 1987;West \& Prinz, 1987). In addition to parental factors, shared environmental factors (any environmental factor making family members resemble one another) can also influence behavior problems outside the home. For example, 'school hassles' were related to both anxiety and conduct problems in a sample of 3rd- and 4th-grade students-although when all areas of daily school experiences and major life events were taken into consideration, only hassles with peers uniquely predicted anxiety whereas hassles with teachers uniquely predicted conduct problems (Barrett \& Heubeck, 2000). Although these in- fluences are considered here as examples of shared environment, it is important to note that several of these factors (e.g., alcoholism: Kendler, Prescott, Neale, \& Pedersen, 1997) are mediated at least in part by genetic factors.

\section{Genetic Effects}

In addition to shared environmental factors, genetic factors also contribute to the association between anxiety and conduct problems, particularly for boys. The bivariate correlation for genetic factors (.31 for boys and .16 for girls) indicated that some genetic factors are common between the two behavioral problems. However, most genetic influence on both anxiety and conduct problems is unique to each problem. Nonetheless, the finding of some genetic overlap has implications for molecular genetic studies, as genes found to be associated with one of these behavioral problems may also influence the other. Although this study was not designed to identify genes common to anxiety and conduct problems, those involved in dopaminergic or serotonergic function are regarded as strong candidates for the association between 
internalizing and externalizing problems. For example, some studies associate low levels of plasma dopamine- $\beta$-hydroxylase with undersocialised conduct disorder (Bowden, Deutsch, \& Swanson, 1988; Rogeness, Hernandez, Macedo, \& Mitchell, 1982); and neural circuits involving dopamine are considered important in both animal and human aggression (Miczek, Fish, de Bold, \& de Almeida, 2002). Furthermore, dopaminergically mediated striatal circuits are postulated to be important in social anxiety disorder (Stein, Westenberg, \& Liebowitz, 2002). Similarly, dysregulation of serotonin function has been implicated in studies of aggression (Unis et al., 1997), and a variety of serotonin markers are important in anxiety (for a review see Eley et al., 2002). Despite the importance of dopamine and serotonin to both anxiety and conduct problems, it is currently unclear as to how such genes function so as to influence these two problems in similar ways, and much of the literature highlights ways in which they differ (e.g., Pliszka et al., 1988). One possibility however stems from acknowledging that anxiety and conduct can involve high levels of reactivity to threat or challenge. For example, reactive aggression and explosiveness may occur in children with conduct problems, and anxious children may react strongly (e.g. crying) to mild stressors. It is therefore possible that a modulatory neurotransmitter such as serotonin plays a role in regulating the reactivity of complex emotional substrates in the brain that are dysregulated in children with both anxiety and conduct problems.

\section{Nonshared Environmental Effects}

The contribution of nonshared environmental influence to the phenotypic association between the two measures was small and negative, indicating that influences that result in an increase in anxiety problems lead to a decrease in conduct problems, and vice versa. In addition to life events (discussed previously), a further candidate environmental influence on anxiety and conduct problems is parent-child interactions. For example, although mothers of aggressive children often fail to impose clear boundaries on the latter's behavior and are more likely to comply with their children's demands, mothers of anxious children typically use high levels of control and resist being controlled by their children (Dumas, Serketich, \& Lafreniere, 1995). It is therefore possible that letting a child get away with inappropriate behavior is more likely to lead to higher levels of conduct problems and lower levels of anxiety, whereas a strict approach to childrearing could lead to higher levels of anxiety and lower levels of conduct problems. Although parenting is typically considered to be an aspect of the shared environment, it can also act so as not to make family members resemble one another, through differential relationships between different family members, thereby acting as a nonshared environmental influence. Such influences are probably of little importance given the small influence of nonshared environment on the association between anxiety and conduct problems.

\section{Limitations}

Despite the obvious advantages of this study, including the large sample size and community sample, several limitations need to be addressed. General limitations to twin studies include the possibility that MZ twins experience more similar environments than DZ twins (a violation of the equal environments assumption). This would artificially inflate estimates of heritability. Research investigating this issue, however, suggests that the more similar environments experienced by MZ twins are due to genetic similarities between the twins causing them to elicit or produce more similar environments (Kendler, Neale, Kessler, Heath, \& Eaves, 1993). A further general limitation concerns chorionicity. Although two thirds of MZ twins are monochorionic (share one sack within the amnion), all DZ twins are dichorionic (have separate sacks within the amnion). Increased similarity in gestational environment in monochorionic MZ twins could also artificially inflate heritability, but the evidence for this is weak (Plomin et al., 2001). Neither of these limitations is likely to be important in interpreting the results of this investigation, because heritability was not overwhelmingly influential. The main finding from this study concerns the overlapping shared environmental influences on anxiety and conduct problems.

Several limitations specific to this study should also be noted. The first concerns the use of a single parent to rate anxiety and conduct problems in both twins, an issue mentioned earlier in relation to the finding of shared environment. Although parental reports are useful in 
the assessment of behavioral problems in children, they may be subject to methodological problems such as rater bias which, in the present context, is the tendency for a rater to consistently over- or under-estimate behavioral problems for both twins which can lead to an overestimation of shared environmental parameters. Although rater bias may partially account for the high bivariate correlation for the shared environment, the modest phenotypic correlation (about .35) between anxiety and conduct, and the different estimates for genetic, shared, and nonshared environment for anxiety and conduct, indicate that parents were able to distinguish these two phenotypes. Furthermore, previous studies of different co-occurring phenotypes have relied on parental reports on more than one phenotype, yet have not shown such high shared environmental influences (Schmitz et al., 2001; Silberg et al., 1996), which suggests that the importance of shared environment reported in this investigation is not just a result of biased reporting. Obtaining observational data or data from multiple raters would have attenuated problems caused by using a single rater. Although observational ratings were not feasible on this large sample, teacher ratings of the TEDS sample are being obtained when the twins are 7 years old. Finally, although we tested three multivariate models to attempt to understand more about the structure of the association between these two variables, the correlated factors model has the least constrained structure and as such is always likely to provide the best fit. However, the other models provided substantially worse fits to these data, suggesting that the finding that the correlated factors model provides the best description of the structure of these data is not just an artifact of its saturation.

\section{Conclusions}

In conclusion, this study highlights the importance of shared environmental factors in the association between anxiety and conduct problems in young children. This is important given the relative infrequency of this parameter in univariate behavioral genetic studies, and suggests that there may be important differences in the etiology of single phenotypes as compared to their covariation. This has important implications for future research, suggesting that close attention to aspects of the familial environment- such as parent-child relationships-may be a useful starting point for understanding and potentially preventing and treating the covariation of anxiety and conduct problems in children.

\section{Acknowledgements}

The authors thank the participants in the Twins Early Developmental Study (TEDS). We also thank Tara McKearney, Andrew McMillan, and Angelica Ronald for their help and assistance. TEDS is supported by a program grant from the U.K. Medical Research Council (MRC). The first author is supported by a Studentship awarded by the U.K. MRC. The second author is supported by a Career Development Award from the MRC.

\section{References}

Anderson, J. C., Williams, S., McGee, R., \& Silva, A. (1987). DSM-III disorders in preadolescent children. Archives of General Psychiatry, 44, 69-80.

Barrett, P. M., Rapee, R. M., Dadds, M. M., \& Ryan, S. M. (1996). Family enhancement of cognitive style in anxious and aggressive children. Journal of Abnormal Child Psychology, 24, 187-203.

Barrett, S., \& Heubeck, B. G. (2000). Relationships between school hassles and uplifts and anxiety and conduct problems in grades 3 and 4. Journal of Applied Developmental Psychology, 21, 537-554.

Behar, L., \& Stringfield, S. (1974). A behavior rating scale for the preschool child. Developmental Psychology, 33, 3-66.

Berden, G. F. M., Aalhaus, M.,\&Verhulst, F. C. (1990). Major life events and changes in the behavioral functioning of children. Journal of Child Psychology and Psychiatry, 31, 949-959. 
Bowden, C. L., Deutsch, C. K., \& Swanson, J. M. (1988). Plasma dopamine-beta-hydroxylase and platelet monoamine-oxidase in attention deficit disorder and conduct disorder. Journal of the American Academy of Child and Adolescent Psychiatry, 27, 171-174.

Dadds, M. R., Barrett, P. M., Rapee, R. M., \& Ryan, S. (1996). Family process and child anxiety and aggression: An observational analysis. Journal of Abnormal Child Psychology, 24, 715-734.

Dadds, M. R., \& Roth, J. H. (2001). Family processes in the development of anxiety problems. In M. W.Vasey \& M. R. Dadds (Eds.), The developmental psychopathology of anxiety (pp. 278-304). New York: Oxford University Press.

Dumas, J. E., Serketich, W. J., \& Lafreniere, P. J. (1995). Balance of power-A transactional-analysis of control in mother-child dyads involving socially competent, aggressive, and anxious children. Journal of Abnormal Psychology, 104, 104-113.

Eley, T. C., Collier, D., \& McGuffin, P. (2002). Anxiety and eating disorders. In P. McGuffin, I. I. Gottesman,\&M.Owen(Eds.), Psychiatric genetics and genomics (pp. 303-340). Oxford: Oxford University Press.

Eley, T. C.,\&Gregory,A.M. (in press). Behavioral genetics. In T. Morris \& J. March (Eds.), Anxiety disorders in children and adolescents (2nd ed.). New York: Guilford.

Eley, T. C., Lichtenstein, P., \& Moffitt, T. E. (2003). A longitudinal behavioral genetic analysis of the etiology of aggressive and nonaggressive antisocial behavior. Development and Psychopathology, 15, 383-402.

Eley, T. C., \& Stevenson, J. (1999). Using genetic analyses to clarify the distinction between depressive and anxious symptoms in children and adolescents. Journal of Abnormal Child Psychology, 27, 105- 114.

Farrington, D. P. (1995). The development of offending and antisocial behaviour from childhood: Key findings from the Cambridge study in delinquent development. Journal of Child Psychology and Psychiatry, 360, 929-964.

Fergusson, D. M., \& Horwood, L. J. (1993). The structure, stability and correlations of the trait components of conduct disorder, attention deficit and anxiety/withdrawal reports. Journal of Child Psychology and Psychiatry, 34, 749-766.

Gjone, H.,\&Stevenson, J. (1997). The association between internalizing and externalizing behavior in childhood and early adolescence: Genetic or environmental common influences? Journal of Abnormal Child Psychology, 25, 277-286.

Goodman, R. (1997). The strengths and difficulties questionnaire: A research note. Journal of Child Psychology and Psychiatry, 38, 581-586.

Hogg, C., Rutter, M.,\&Richman, N. (1997). Emotional and behavioural problems in children. In I. Insclare (Ed.), Child psychology portfolio. Windsor: NFER-Nelson.

Jaffee, S. R., Moffitt, T. E., Caspi, A., Taylor, A., \& Arseneault, L. (2002). Influence of adult domestic violence on children's internalizing and externalizing problems: An environmentally informative twin study. Journal of the American Academy of Child and Adolescent Psychiatry, 41, 1095-1103.

Johnson, J. G., Cohen, P., Dohrenwend, B. P., Link, B. G., \& Brook, J. S. (1999). A longitudinal investigation of social causation and social selection processes involved in the association between socioeconomic status and psychiatric disorders. Journal of Abnormal Psychology, 108, 490-499.

Kendler, K. S., Neale, M. C., Kessler, R. C., Heath, A. C., \& Eaves, L. J. (1993). A test of the equalenvironment assumption in twin studies of psychiatric illness. Behavior Genetics, 23, 21-27.

Kendler, K. S., Prescott, C. A., Neale, M. C., \& Pedersen, N. L. (1997). Temperance Board registration for alcohol abuse in a national sample of Swedish male twins, born 1902 to 1949. Archives of General Psychiatry, 54, 178-184.

Lewis, M., Feiring, C., McGuffog, C., \& Jaskir, J. (1984). Predicting psychopathology in 6-year-olds from early social-relations. Child Development, 55, 123-136. 
Linver, M. R., Brooks-Gunn, J., \& Kohen, D. E. (2002). Family processes as pathways from income to young children's development. Developmental Psychology, 38, 719-734.

McCartney, K., Harris, M. J., \& Bernieri, F. (1990). Growing up and growing apart:Adevelopmental metaanalysis of twin studies. Psychological Bulletin, 107, 226-237.

Miczek, K. A., Fish, E. W., de Bold, J. F., \& de Almeida, R. M. M. (2002). Social and neural determinants of aggressive behavior: Pharmacotherapeutic targets at serotonin, dopamine and gamma-aminobutyric acid systems. Psychopharmacology, 163, 434-458.

Neale, M. C. (1997). Mx: Statistical modeling (4th ed.). Box 126 MCV, Richmond, VA 23298: Department of Psychiatry.

Neale, M. C.,\&Cardon, L. R. (1992). Methodology for genetic studies of twins and families. Dordrecht, The Netherlands: Kluwer Academic. Neale, M. C., \& Kendler, K. S. (1995). Models of comorbidity for multifactorial disorders. American Journal of Human Genetics, 57, 935- 953.

O’Connor, T. G., McGuire, S., Reiss, D., Hetherington, E. M.,\&Plomin, R. (1998). Co-occurrence of depressive symptoms and antisocial behavior in adolescence: A common genetic liability. Journal of Abnormal Psychology, 107, 27-37.

O'Connor, T. G., Neiderhiser, J. M., Reiss, D., Hetherington, E. M., \& Plomin, R. (1998). Genetic contributions to continuity, change, and co-occurrence of antisocial and depressive symptoms in adolescence. Journal of Child Psychology and Psychiatry, 39, 323-336.

Pike, A., \& Plomin, R. (1996). Importance of nonshared environmental factors for childhood and adolescent psychopathology. Journal of the American Academy of Child and Adolescent Psychiatry, 35, 560-570.

Pliszka, S. R., Rogeness, G. A., Renner, P., Sherman, J., \& Broussard, T. (1988). Plasma neurochemistry in juvenile-offenders. Journal of the American Academy of Child and Adolescent Psychiatry, 27, 588-594.

Plomin, R., DeFries, J. C., McClearn, G. E., \& McGuffin, P. (2001). Behavioral Genetics (4th ed.). New York: Worth.

Price, T. S., Freeman, B., Craig, I. W., Petrill, S. A., Ebersole, L., \& Plomin, R. (2000). Infant zygosity can be assigned by parental report questionnaire data. Twin Research, 2000, 129-133.

Price, T. S., Petrill, S. A., Dale, P. S., \& Plomin, R. (2003). A longitudinal multivariate genetic analysis of verbal and nonverbal cognitive abilities in early childhood. Manuscript submitted for publication.

Rogeness, G. A., Hernandez, J. M., Macedo, C. A., \& Mitchell, E. L. (1982). Biochemical differences in children with conduct disorder socialized and under-socialized. American Journal of Psychiatry, 139, 307311.

Ronald, A., Eley, T. C., \& Plomin, R. (2003). Behavior problems in early childhood: Genetic and environmental etiologies across the whole spectrum of individual variation and at the problem end. Manuscript submitted for publication.

Rosenstein, D. S.,\&Horowitz, H. A. (1996). Adolescent attachment and psychopathology. Journal of Consulting and Clinical Psychology, 64, 244-253.

Russo, M. F., \& Beidel, D. C. (1994). Comorbidity of childhood anxiety and externalizing disorders: Prevalence, associated characteristics, and validation issues. Clinical Psychology Review, 14, 199-221.

Schmitz, S., Cherny, S. S., Fulker, D. W., \& Mrazek, D. A. (1994). Genetic and environmental influences on early childhood behavior. Behavior Genetics, 24, 25-34.

Schmitz, S.,\&Mrazek, D. (2001). Genetic and environmental influences on the associations between attention problems and other problem behaviors. Twin Research, 4, 453-458.

Silberg, J., Rutter, M., Neale, M.,\&Eaves, L. (2001). Genetic moderation of environmental risk for depression and anxiety in adolescent girls. British Journal of Psychiatry, 179, 116-121. 
Silberg, J. L., Rutter, M. L., Meyer, J., Maes, H., Hewitt, J., Simonoff, E., et al. (1996). Genetic and environmental influences on the covariation between hyperactivity and conduct disturbance in juvenile twins. Journal of Child Psychology and Psychiatry, 37, 803-816.

Stein, D. J., Westenberg, H. G. M., \& Liebowitz, M. R. (2002). Social anxiety disorder and generalized anxiety disorder: Serotonergic and dopaminergic neurocircuitry. Journal of Clinical Psychiatry, 63, 12-19.

Strauss, C. C., Lease, C. A., Last, C. G., \& Francis, G. (1988). Overanxious disorder: An examination of developmental differences. Journal of Abnormal Child Psychology, 16, 433-443.

Thapar, A., \& McGuffin, P. (1997). Anxiety and depressive symptoms in childhood-a genetic study of comorbidity. Journal of Child Psychology and Psychiatry, 38, 651-656.

Trouton, A., Spinath, F. M., \& Plomin, R. (2002). Twins Early Development Study (TEDS): A multivariate, longitudinal genetic investigation of language, cognition and behavior problems in childhood. Twin Research, 5, 444-448.

Unis, A. S., Cook, E. H., Vincent, J. G., Gjerde, D. K., Perry, B. D., Mason, C., et al. (1997). Platelet serotonin measures in adolescents with conduct disorder. Biological Psychiatry, 42, 553-559.

Van den Oord, J. C. G., Boomsma, D. I., \& Verhulst, F. C. (2000). A study of genetic and environmental effects on the co-occurrence of problem behaviors in three-year-old twins. Journal of Abnormal Psychology, $109,360-372$.

van Ijzendoorn, M. H., \& Bakermans-Kranenburg, M. J. (1996). Attachment representations in mothers, fathers, adolescents, and clinical groups: A meta-analytic search for normative data. Journal of Consulting and Clinical Psychology, 64, 8-21.

Werry, J. S., Reeves, J. C.,\&Elkind, G. S. (1987). Attention-deficit, conduct, oppositional, and anxiety disorders in children .1. A review of research on differentiating characteristics. Journal of the American Academy of Child and Adolescent Psychiatry, 26, 133-143.

West, M. O., \& Prinz, R. J. (1987). Parental alcoholism and childhood psychopathology. Psychological Bulletin, 102, 204-218.

Windle, M., \& Windle, R. C. (1996). Coping strategies, drinking motives, and stressful life events among middle adolescents: Associations with emotional and behavioral problems and with academic functioning. Journal of Abnormal Psychology, 105, 551-560. 
Table I. Items in the Anxiety and Conduct Scales of the Revised Rutter Parent Scale for Preschool Children

Items in the Anxiety Scale
Is worried, worries about many things
Tends to do things on own, rather solitary
Appears miserable, unhappy, tearful or distressed
Tends to be afraid of new things or new situations
Fussy, or over particular
Cries easily
Items in the Conduct Scale
Destroys own or other's belongings
Fights with other children
Is disobedient
Tells lies
Bullies other children
Blames others for things
Inconsiderate of others
Kicks, bites other children

Table II. Means (With Standard Deviations) for the Outcomes by Twin Type

\begin{tabular}{|c|c|c|c|c|c|c|}
\hline & \multirow[b]{2}{*}{ MZM } & \multirow[b]{2}{*}{ DZM } & \multirow[b]{2}{*}{ MZF } & \multirow[b]{2}{*}{ DZF } & \multicolumn{2}{|c|}{ DZF } \\
\hline & & & & & Males & Females \\
\hline $\begin{array}{l}\text { Anxiety problems } \\
\text { at } 2\end{array}$ & $.27(.16)[858]$ & $.30(.17)[968]$ & $\begin{array}{l}.29(.16) \\
{[1010]}\end{array}$ & $.31(.17)[891]$ & $.31(.17)$ & $\begin{array}{l}.28(.16) \\
{[1833 a]}\end{array}$ \\
\hline $\begin{array}{l}\text { Anxiety problems } \\
\text { at } 3\end{array}$ & $.28(.17)[846]$ & $.31(.19)[922]$ & $.30(.18)$ [985] & $.32(.19)$ [897] & $.31(.18)$ & $\begin{array}{l}.30(.17) \\
{[1779 a]}\end{array}$ \\
\hline $\begin{array}{l}\text { Anxiety problems } \\
\text { at } 4\end{array}$ & $.15(.15)[711]$ & .19 (.17) [753] & $.16(.15)$ [803] & $.18(.17)$ [743] & $.19(.17)$ & $\begin{array}{l}.16(.15) \\
{[1462 a]}\end{array}$ \\
\hline Anxiety problems & $.24(.14)$ & $.28(.16)$ & $.26(.15)$ & $.28(.16)$ & $.28(.15)$ & $.26(.14)$ \\
\hline Mean & [1073] & [1155] & [1218] & [1116] & & [2231a] \\
\hline $\begin{array}{l}\text { Conduct } \\
\text { problems at } 2\end{array}$ & $.28(.17)$ [852] & $.29(.17)[959]$ & $\begin{array}{l}.26(.16) \\
{[1003]}\end{array}$ & $.26(.17)[889]$ & $.28(.17)$ & $\begin{array}{l}.25(.17) \\
{[1823 a]}\end{array}$ \\
\hline $\begin{array}{l}\text { Conduct } \\
\text { problems at } 3\end{array}$ & $.30(.17)$ [845] & $\begin{array}{l}.29(.18) \\
[920]]\end{array}$ & $.25(.16)$ [982] & $.26(.17)[891]$ & $.29(18)$ & $\begin{array}{l}.25(.16) \\
{[1776 a]}\end{array}$ \\
\hline $\begin{array}{l}\text { Conduct } \\
\text { problems at } 4\end{array}$ & $.24(.17)$ [709] & $.25(.17)$ [752] & $.20(.15)[800]$ & $.20(.15)[741]$ & $.24(.16)$ & $\begin{array}{l}.19(.15) \\
{[1461 a]}\end{array}$ \\
\hline $\begin{array}{l}\text { Conduct } \\
\text { problems Mean }\end{array}$ & $\begin{array}{l}.28(.15) \\
{[1074]}\end{array}$ & $\begin{array}{l}.28(.16) \\
{[1154]}\end{array}$ & $\begin{array}{l}.24(.14) \\
{[1217]}\end{array}$ & $\begin{array}{l}.25(.14) \\
{[1115]}\end{array}$ & $.27(.15)$ & $\begin{array}{l}.24(.14) \\
{[2227 a]}\end{array}$ \\
\hline
\end{tabular}

Note. $\mathrm{MZM}=$ monozygotic male twin pairs; $\mathrm{DZM}=$ dyzygotic male twin pairs; $\mathrm{MZF}=$ monozygotic female twin pairs; $\mathrm{DZF}$ = dyzygotic female twin pairs; $D Z O=D$ dizygotic male-female twin pairs. Numbers in [ ] are for number of twin pairs in each group. "Mean" refers to composite scores, which take the mean of anxiety/conduct problems at ages 2, 3, and 4 (participants provided data at one or more time points). aNumber of DZO male and female twin pairs. 
Table III. Twin Correlations for Anxiety and Conduct Problems

\begin{tabular}{|c|c|c|c|c|}
\hline Trait & $\begin{array}{l}\text { Anxiety problems } \\
\text { twin } 1\end{array}$ & $\begin{array}{l}\text { Conduct problems } \\
\text { twin } 1\end{array}$ & $\begin{array}{l}\text { Anxiety problems } \\
\text { twin } 2\end{array}$ & $\begin{array}{l}\text { Conduct problems } \\
\text { twin } 2\end{array}$ \\
\hline & \multicolumn{4}{|c|}{ MZM twins } \\
\hline Anxiety problems twin 1 & 1.00 & & & \\
\hline Conduct problems twin 1 & .36 & 1.00 & & \\
\hline Anxiety problems twin 2 & .61 & .36 & 1.00 & \\
\hline Conduct problems twin 2 & .34 & $\begin{array}{l}.77 \\
\text { DZN }\end{array}$ & twins & 1.00 \\
\hline Anxiety problems twin 1 & 1.00 & & & \\
\hline Conduct problems twin 1 & .37 & 1.00 & & \\
\hline Anxiety problems twin 2 & .25 & .29 & 1.00 & \\
\hline Conduct problems twin 2 & .34 & $\begin{array}{l}.48 \\
\mathrm{MZ}\end{array}$ & twins & 1.00 \\
\hline Anxiety problems twin 1 & 1.00 & & & \\
\hline Conduct problems twin 1 & .33 & 1.00 & & \\
\hline Anxiety problems twin 2 & .62 & .32 & 1.00 & \\
\hline Conduct problems twin 2 & .33 & $\begin{array}{l}.76 \\
\mathrm{DZ}\end{array}$ & twins & 1.00 \\
\hline Anxiety problems twin 1 & 1.00 & & & \\
\hline Conduct problems twin 1 & .28 & 1.00 & & \\
\hline Anxiety problems twin 2 & .32 & .40 & 1.00 & \\
\hline Conduct problems twin 2 & .36 & $\begin{array}{l}.51 \\
\mathrm{DZ}\end{array}$ & twins & 1.00 \\
\hline Anxiety problems twin 1 & 1.00 & & & \\
\hline Conduct problems twin 1 & .31 & 1.00 & & \\
\hline Anxiety problems twin 2 & .37 & .34 & 1.00 & \\
\hline Conduct problems twin 2 & .34 & .51 & .30 & 1.00 \\
\hline
\end{tabular}

Table IV. Model Fitting Results of Bivariate Behavioral Genetic ACE Models for Anxiety and Conduct Problems

\begin{tabular}{|c|c|c|c|c|c|c|c|c|c|}
\hline Model & $x^{2}$ & $d f$ & $P$ & $\mathrm{AIC}$ & RMSEA & Comp & $\Delta \mathrm{X}^{2}$ & $d f$ & $p$ \\
\hline $\begin{array}{l}\text { 1. Common } \\
\text { pathways model }\end{array}$ & 369.481 & 41 & .000 & 287.481 & .070 & & & & \\
\hline $\begin{array}{l}\text { 2. Common } \\
\text { pathways model } \\
\text { (sex effects) }\end{array}$ & 310.996 & 32 & .000 & 246.996 & .064 & 1 & 58.485 & 9 & $<.001$ \\
\hline $\begin{array}{l}\text { 3. Independent } \\
\text { pathways model }\end{array}$ & 380.056 & 41. & .000 & 298.056 & .071 & & & & \\
\hline $\begin{array}{l}4 \text { Independent } \\
\text { pathways model } \\
\text { (sex effects) }\end{array}$ & 349.929 & 32 & .000 & 285.929 & .068 & 3 & 30.127 & 9 & $<.001$ \\
\hline $\begin{array}{l}\text { 5. Correlated } \\
\text { factors model }\end{array}$ & 341.461 & 41. & .000 & 259.461 & .068 & & & & \\
\hline $\begin{array}{l}6 \text { Correlated } \\
\text { factors modela (sex } \\
\text { effects) }\end{array}$ & 273.370 & 32 & .000 & 209.370 & .060 & 5 & 68.091 & 9 & $<.001$ \\
\hline
\end{tabular}

Table V. Parameter Estimates (With 95\% Confidence Intervals) for the Bivariate Behavioral Genetic Models

\begin{tabular}{|c|c|c|c|c|c|c|c|c|}
\hline \multicolumn{3}{|c|}{ Anxiety problems } & \multicolumn{3}{|c|}{ Conduct problems } & \multicolumn{3}{|c|}{ Bivariate correlations } \\
\hline $\begin{array}{l}a^{2} \\
\text { Males }\end{array}$ & $c^{2}$ & $e^{2}$ & $a^{2}$ & $c^{2}$ & $e^{2}$ & $r_{\mathrm{A}}$ & $r_{\mathrm{C}}$ & $r_{\mathrm{E}}$ \\
\hline $\begin{array}{l}.38(.31- \\
.44)\end{array}$ & $\begin{array}{l}.19(.15- \\
.23)\end{array}$ & $\begin{array}{l}.43(.39- \\
.47)\end{array}$ & $\begin{array}{l}.53(.46- \\
.53)\end{array}$ & $\begin{array}{l}.24(.20- \\
.31)\end{array}$ & $\begin{array}{l}.23(.21- \\
.23)\end{array}$ & $\begin{array}{l}.31(.22- \\
.38)\end{array}$ & $\begin{array}{l}1.00(.94- \\
1.00)\end{array}$ & $\begin{array}{l}\circ .08\left(^{\circ} .13-\right. \\
\circ .07)\end{array}$ \\
\hline $\begin{array}{l}\text { Females } \\
.36(.30- \\
.42)\end{array}$ & $\begin{array}{l}.22(.18- \\
.27)\end{array}$ & $\begin{array}{l}.42(.38- \\
.45)\end{array}$ & $\begin{array}{l}.38(.31- \\
.45)\end{array}$ & $\begin{array}{l}.37(.30- \\
.43)\end{array}$ & $\begin{array}{l}.25(.23- \\
.28)\end{array}$ & $\begin{array}{l}.16(.04- \\
.25)\end{array}$ & $\begin{array}{l}.99(.96- \\
1.00)\end{array}$ & $\begin{array}{l}0.14\left(^{\circ} .14-\right. \\
.08)\end{array}$ \\
\hline
\end{tabular}

Note. These parameter estimates come from the bivariate model of best fit, which is an ACE correlated factors model, allowing for sex differences in the parameter estimates. The anxiety and conduct problems scores used in these analyses are the composites (the mean scores at ages 2,3 , and 4 ). 


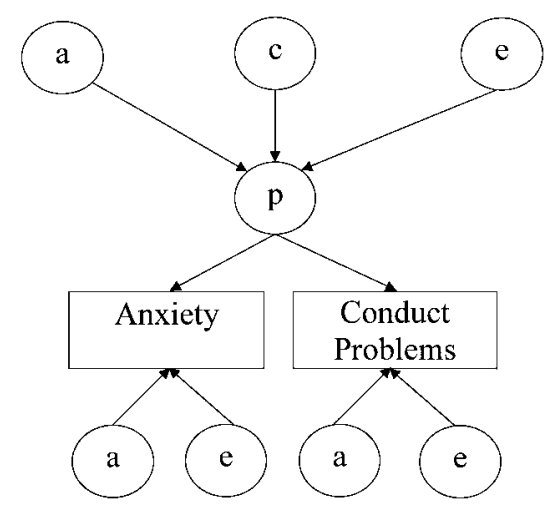

Fig. 1. Common pathways model. $A=$ additive genetic effects; $C=$ shared environmental effects; $E=$ non-shared environmental effects; $P=$ underlying phenotype.

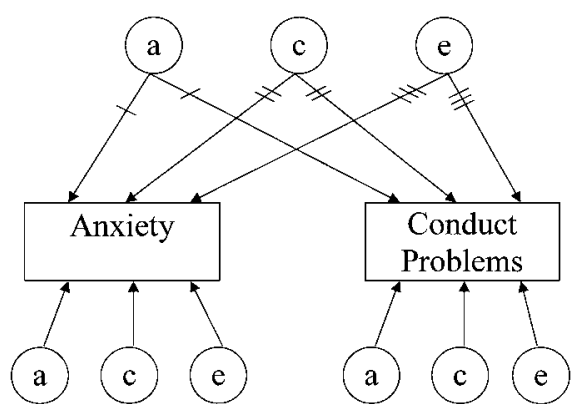

Fig. 2. Independent pathways model. A = additive genetic effects; $C=$ shared environmental effects; $E=$ nonshared environmental effects.

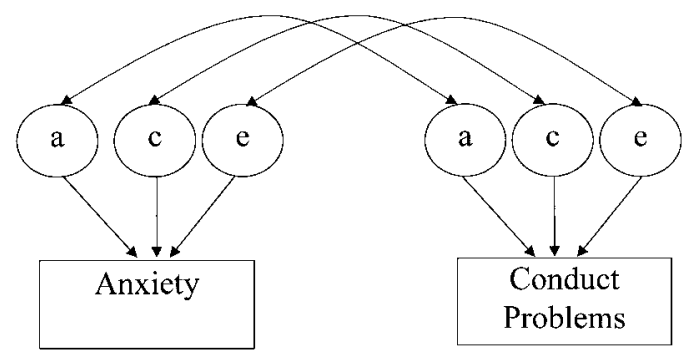

Fig. 3. Correlated factors model. $A$ = additive genetic effects; $C$ = shared environmental effects; $E$ = nonshared environmental effects.

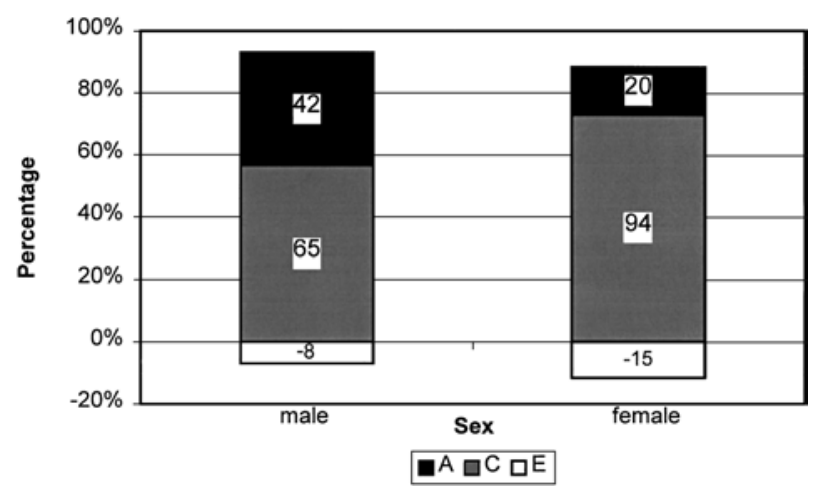

Fig. 4. Proportion of phenotypic correlation due to $A, C$, and $E$. $A=$ additive genetic effects; $C=$ shared environmental effects; $E$ = nonshared environmental effects. Note. The phenotypic correlation between anxiety and conduct problems is .33 for boys and .30 for girls. 